OPEN ACCESS

Edited by:

Ildikó Rácz,

Universitätsklinikum Bonn, Germany

Reviewed by:

Wei Xiong,

University of Science and Technology

of China, China

Luis F. Callado,

Universidad del País Vasco, Spain

Anissa Bara,

Icahn School of Medicine at Mount

Sinai, United States

*Correspondence:

Diego Centonze

centonze@uniroma2.it

Received: 27 August 2018 Accepted: 31 October 2018 Published: 20 November 2018

Citation:

Stampanoni Bassi M, Gilio L, Maffei $P$

Dolcetti $E$, Bruno A, Buttari F,

Centonze D and lezzi $E$ (2018)

Exploiting the Multifaceted Effects of

Cannabinoids on Mood to Boost Their

Therapeutic Use Against Anxiety and

Depression

Front. Mol. Neurosci. 11:424. doi: 10.3389/fnmol.2018.00424

\section{Exploiting the Multifaceted Effects of Cannabinoids on Mood to Boost Their Therapeutic Use Against Anxiety and Depression}

\author{
Mario Stampanoni Bassi ${ }^{1}$, Luana Gilio ${ }^{1,2}$, Pierpaolo Maffei ${ }^{1}$, Ettore Dolcetti ${ }^{2}$, \\ Antonio Bruno ${ }^{2}$, Fabio Buttari ${ }^{1}$, Diego Centonze ${ }^{1,2 \star}$ and Ennio lezzi ${ }^{1}$ \\ ${ }^{1}$ Unit of Neurology and Neurorehabilitation, IRCCS Neuromed, Pozzilli, Italy, ${ }^{2}$ Laboratory of Synaptic Immunopathology, \\ Department of Systems Medicine, Tor Vergata University, Rome, Italy
}

The endocannabinoid system (ECS) has been recently recognized as a prominent promoter of the emotional homeostasis, mediating the effects of different environmental signals including rewarding and stressing stimuli. The ECS modulates the rewarding effects of environmental stimuli, influencing synaptic transmission in the dopaminergic projections to the limbic system, and mediates the neurophysiological and behavioral consequences of stress. Notably, the individual psychosocial context is another key element modulating the activity of the ECS. Finally, inflammation represents an additional factor that could alter the cannabinoid signaling in the CNS inducing a "sickness behavior," characterized by anxiety, anhedonia, and depressive symptoms. The complex influences of the ECS on both the environmental and internal stimuli processing, make the cannabinoid-based drugs an appealing option to treat different psychiatric conditions. Although ample experimental evidence shows beneficial effects of ECS modulation on mood, scarce clinical indication limits the use of cannabis-based treatments. To better define the possible clinical indications of cannabinoid-based drugs in psychiatry, a number of issues should be better addressed, including genetic variability and psychosocial factors possibly affecting the individual response. In particular, better knowledge of the multifaceted effects of cannabinoids could help to understand how to boost their therapeutic use in anxiety and depression treatment.

Keywords: endocannabinoids, reward, stress, depression, anxiety, multiple sclerosis, EAE, inflammation

\section{ENDOCANNABINOID SYSTEM}

The endocannabinoid system (ECS) consists of endocannabinoids (eCBs), cannabinoid receptors (CBRs), biosynthesizing, and degrading enzymes. The main eCBs, anandamide (AEA) and 2arachidonoyl-glycerol (2-AG), are degraded by distinct enzymes, the fatty-acid amide hydrolase (FAAH) and monoacylglycerol lipase (MAGL), respectively. eCBs interact with a number of different molecular targets (Howlett et al., 2002) as the two CBRs (CB1R and CB2R) and with other G protein-coupled receptors (GPCRs) including GPR55 and GPR119, GPR18 which are expressed in different tissues, including the immune cells, and mediate a wide range of physiological functions (Chiang et al., 2015; Morales and Reggio, 2017). Furthermore, eCBs bind to other receptor subtypes, as the transient receptor potential vanilloid type 1 (TRPV1) cation channel (Tóth et al., 2009), 
the peroxisome proliferator-activated receptor, and glycine receptors (Zhang and Xiong, 2009). Finally, it has been demonstrated that CBRs can form heterodimers with other receptors including serotonin (5-HT), opioid and dopamine (DA) receptors (Farran, 2017).

Numerous physiological functions, as mood, cognition, feeding behavior and pain perception, are modulated by the ECS (Di Marzo et al., 1998; Di Marzo, 2009; Castillo et al., 2012; Pacher and Kunos, 2013). CB1Rs represent the most numerous GPCRs in the adult brain, particularly expressed in regions involved in reward, addiction and cognitive functions, including the amygdala, cingulate cortex, prefrontal cortex, ventral pallidum, caudate, nucleus accumbens, ventral tegmental area, and lateral hypothalamus (Glass et al., 1997; Wang et al., 2003). Synaptic transmission is controlled by the eCBs through a physiological feedback mechanism acting to avoid excessive synaptic excitation or inhibition (Lovinger, 2008). In particular, the eCBs act as retrograde messengers (Wilson and Nicoll, 2002) suppressing neurotransmitter release either at $\gamma$-aminobutyric acid (GABA)ergic or glutamatergic synapses (Alger, 2002; Heinbockel et al., 2005). Furthermore, as CB1Rs are mainly located on the presynaptic terminals, eCBs may directly modulate other neurotransmitter pathways as opioid peptides, acetylcholine and 5-HT (Heifets and Castillo, 2009; Kano et al., 2009).

The ECS have a prominent role in maintaining emotional homeostasis, mediating the effects of different environmental signals, including rewarding and stressing stimuli (Parsons and Hurd, 2015). Moreover, recent evidence showed that also the immune system interacts with the ECS. In particular, different inflammatory mediators alter CB signaling in the CNS (Figure 1).

\section{ECS CONTROL OF EMOTIONS AND BEHAVIOR}

The ability to integrate external and internal stimuli to select appropriate behaviors is crucial for individuals. The ECS regulates a number of physiological functions and mediates the crosstalk between different neurotransmitter systems, therefore representing a key player in the control of behavioral responses (Lutz et al., 2015). Indeed, a number of emotions and behaviors, such as fear, anxiety, depression, stress-coping and reward-driven behaviors are critically modulated by the ECS.

In particular, it has been demonstrated that CB1Rs are expressed in brain areas critically involved in the control of mood and behavior, including limbic and frontal regions, and regulate serotonin transmission (Herkenham et al., 1991; Nakazi et al., 2000). Preclinical and human studies evidenced that activity of the ECS regulates anxiety and depression and modulates behavioral responses to stress and reward (Table 1).

\section{The ECS Regulates Depression and Anxiety}

Preclinical studies evidenced that reduced ECS activity induces depressive-like behaviors in animals in different experimental paradigms usually employed to test the antidepressant effects

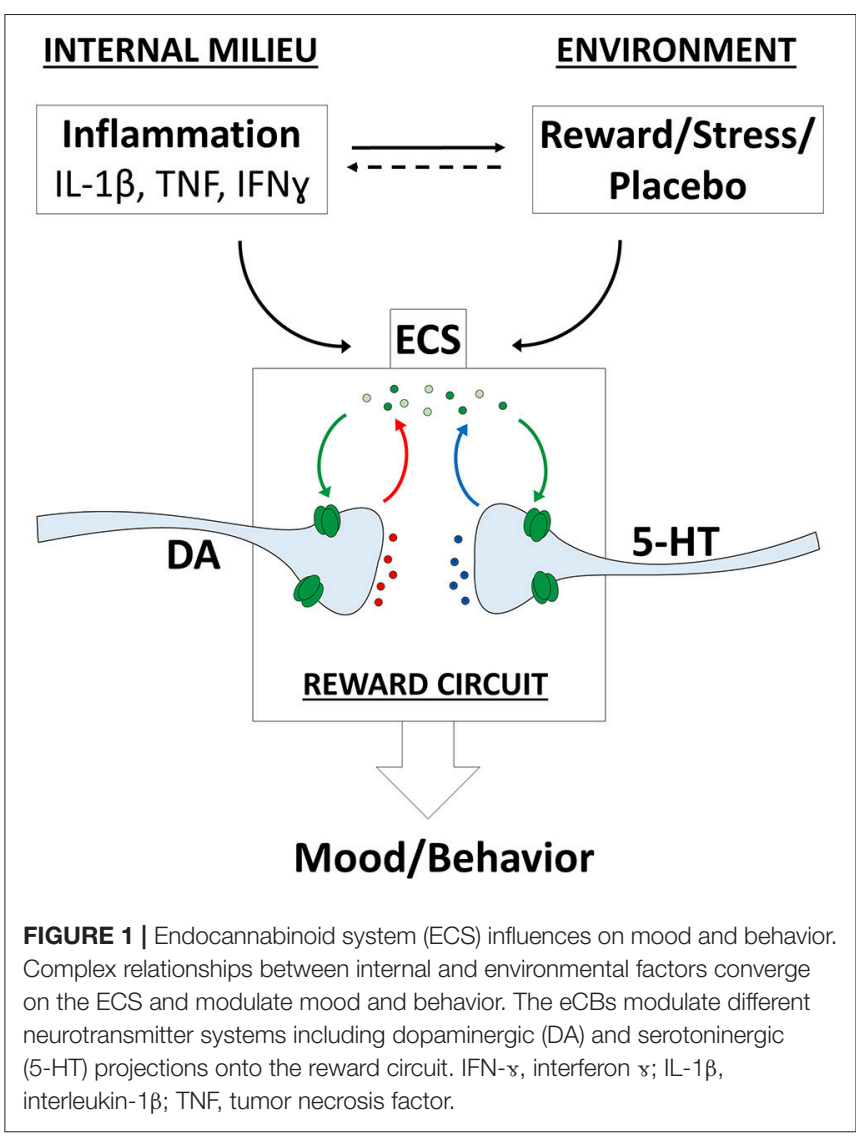

of drugs (Martin et al., 2002; Hill and Gorzalka, 2005a). In particular, CB1R-knock out (CB1R-KO) mice showed increased immobility in the forced-swim test (Uriguen et al., 2003), higher sensitivity to depressive-like responses in the chronic unpredictable mild stress paradigm and increased anxiety-like behavior in the light/dark test (Martin et al., 2002). Moreover, administration of CB1R antagonists increased anxiety-like behavior in the defensive withdrawal test (Navarro et al., 1997) and in the elevated-plus maze test (Navarro et al., 1997; Haller et al., 2004; Patel and Hillard, 2006). In addition, in mice lacking the CB1R both increased anxiety in the elevated-plus maze test (Haller et al., 2004; Mikics et al., 2009) and reduced anxiolytic action of benzodiazepines have been observed (Urigüen et al., 2004). Conversely, enhancing ECS signaling may exert antidepressant and anxiolytic-like effects. In particular, it has been demonstrated that FAAH inhibitors reduced anxiety-like behavior in the elevated-zero maze and in the isolation-induced ultrasonic-emission tests (Kathuria et al., 2003). Moreover, FAAH inhibitors reduced immobility in the tail suspension test and prolonged swimming in the forced swimming test (Gobbi et al., 2005). In addition, similar results were obtained by administration of either CB1R agonists or an eCB uptake inhibitor (Hill and Gorzalka, 2005b; Adamczyk et al., 2008).

It has also been shown that the clinical effect of different antidepressants is mediated by a modulation of ECS activity 
TABLE 1 | Experimental and human studies showing the role of the ECS in the regulation of mood and in mediating the responses to reward, stress and inflammation.

\begin{tabular}{lll}
\hline Author & $\begin{array}{l}\text { Experimental } \\
\text { protocol/model }\end{array}$
\end{tabular}

Navarro et al., 1997

Haller et al., 2004

Hill et al., 2006

Domschke et al., 2008

Centonze et al., 2007

De Chiara et al., 2010

Chen et al., 2008

Zuo et al., 2007

Hohmann et al., 2005

Rademacher and Hillard, 2007

Rossi et al., 2008

Lu et al., 2008

Agrawal et al., 2012
Defensive withdrawal test, elevated plus-maze

Elevated plus-maze Wild type (WT) and CB1R-KO mice

Forced swim test (FST)

Desipramine, FST

CNR1 SNP, Major depression

Cocaine consumption

Running wheel, Sucrose consumption

CNR1 SNP, Nicotine dependance CNR1 SNP, Substance dependence

Stress- induced analgesia (SIA)

Restraint stress

Social defeat stress (SDS)

CNR1 SNP, Attention deficit hyperactivity disorder (ADHD) and post-traumatic stress disorder (PTSD)

CNR1 SNP, Anhedonia
CB1R antagonist administration induced anxiety-like responses in both protocols, without influencing the pattern of horizontal locomotor activity and the total activity in the elevated plus-maze.

The secretion of stress related hormones was not influenced.

CB1R-KO showed higher anxiety-like behavior than the WT.

Administration of the CB1R antagonist AM251 increased anxiety-like behavior in WT but had no effect in the CB1R-KO.

The CB agonist WIN-55,212-2 reduced anxiety-like behavior. The effect of WIN-55,212-2 was abolished by CB1-antagonist only in WT.

Desipramine reduced immobility duration in the FST.

Immobility was significantly reduced by the administration of the eCB uptake inhibitor AM404, the CB1R agonist HU-210, and Oleamide.

The effects of AM404, HU-210 and Oleamide were blocked by pretreatment with the CB1R antagonist AM251.

Three-weeks administration of desipramine increased CB1R density in the hippocampus and hypothalamus.

Chronic desipramine treatment reduced the secretion of corticosterone and the induction of the immediate early gene c-fos in the hypothalamus following a 5 min exposure to swim stress. Acute treatment with the CB1R antagonist AM251 before swim stress, blocked the effects of desipramine.

CNR1 rs1049353 G allele was associated with increased pharmacoresistance to antidepressants. G allele was also associated with reduced bilateral activity in the amygdala, putamen and pallidum, and reduced activity in the left caudate and left thalamus in response to emotional faces.

Seven days of cocaine consumption induced sensitization of striatal GABA synapses to CB1R stimulation by $\mathrm{HU}-210$.

The CB1R-induced modulation of glutamate transmission was unaltered by cocaine.

Running wheel and sucrose consumption induced sensitization of striatal GABA synapses to CB1R stimulation.

Both wheel running or sucrose consumption prevented the effects of stress on striatal GABA synapses.

Variants and haplotypes in the CNR1 gene may play important roles in developing nicotine dependence. These associations seem to be sex specific.

possession of both the $\mathrm{G}$ allele of the) $17937 \mathrm{~T}>\mathrm{G}$ polymorphism (rs6454674) and the $\mathrm{T} / \mathrm{T}$ genotype of the 4893 T > C (rs806368) has been recently associated with a higher risk of AD possession of both the $\mathrm{G}$ allele of the) $17937 \mathrm{~T}>\mathrm{G}$ polymorphism (rs6454674) and the $\mathrm{T} / \mathrm{T}$ genotype of the 4893 T > C (rs806368) has been recently associated with a higher risk of AD possession of both the $\mathrm{G}$ allele of the) $17937 \mathrm{~T}>\mathrm{G}$ polymorphism (rs6454674) and the T/T genotype of the $4893 \mathrm{~T}>\mathrm{C}$ ( $\mathrm{rs806368}$ ) has been recently associated with a higher risk of AD rs6454674 and rs806368 have been significantly associated with a higher risk of drug dependence and alcohol dependence.

Blockade of CB1Rs in the periaqueductal gray (PG) prevents non-opioid SIA.

Stress increases $2 A G$ and AEA levels in the PG.

Both MAGL and FAAH inhibitors enhanced SIA.

Mice exposed to restraint showed reduced preference for sucrose over water.

The effects of restraint stress were reduced by the CB agonist CP55940 or the FAAH inhibitor URB59, and enhanced by the CB1R antagonist rimonabant.

Stress exposure reduced the sensitivity of GABA synapses in the striatum to CB1R stimulation. This alteration was prevented by pharmacological blockade of glucocorticoid receptors and was reproduced by corticosterone injection.

Running wheel, sucrose administration, or a single injection of cocaine promoted the recovery of synaptic defects.

Significant associations were identified between CNR1 SNP haplotypes and both ADHD and PTSD.

History of childhood physical abuse was significantly associated with anhedonia only in rs1049353 GG patients. 
TABLE 1 | Continued

\begin{tabular}{|c|c|c|}
\hline Author & $\begin{array}{l}\text { Experimental } \\
\text { protocol/model }\end{array}$ & Main findings \\
\hline Rossi et al., 2012 & IL-1 $\beta$ injection, SDS & 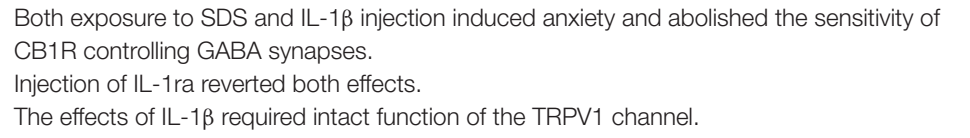 \\
\hline Gentile et al., 2016 & EAE mice, CB1R-KO mice & $\begin{array}{l}\text { EAE-induced anxiety was associated with reduced the sensitivity of GABA synapses in the } \\
\text { striatum to CB1R stimulation. } \\
\text { These alterations were exacerbated in CB1R-KO mice. } \\
\text { IL-1ra administration reduced anxiety in EAE mice, and restored both DA release and the } \\
\text { sensitivity of striatal GABA synapses to CB1R stimulation. }\end{array}$ \\
\hline Mandolesi et al., 2017 & IFN-xinjection, EAE mice & $\begin{array}{l}\text { IFN-xinjection induced anxiety and depression, associated with reduced sensitivity of striatal } \\
\text { GABA synapses to CB1R stimulation. } \\
\text { EAE was associated with increased striatal IFN-rexpression and altered CB1R transmission. } \\
\text { These alterations were rescued by blocking IFN-rsignaling. }\end{array}$ \\
\hline
\end{tabular}

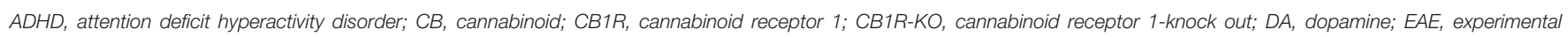

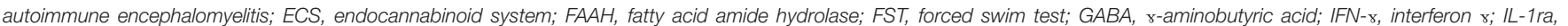

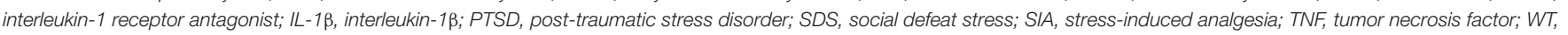
wild type.

in specific brain regions, including the hypothalamus, the amygdala and the hippocampus. In particular, chronic treatment with tricyclic antidepressants was associated with increased CB1R density in the hippocampus and hypothalamus and reduced hypothalamic-pituitary-adrenal (HPA) axis activation in response to stressing stimuli (Hill et al., 2006, 2009a).

It has been evidenced that ECS functionality may influence mood also in humans. In patients with major depression reduced circulating levels of both 2-AG (Hill et al., 2008) and AEA (Hill et al., 2009b) have been described. In addition, chronic treatment with CB1R antagonists has been associated with increased incidence of anxiety and depression. In particular, the $\mathrm{CB} 1 \mathrm{R}$ antagonist rimonabant introduced for smoking cessation and to treat obesity, was suspended following several reports of severe mood depressant action (Després et al., 2005; Van Gaal et al., 2005; Padwal and Majumdar, 2007; Traynor, 2007; Rigotti et al., 2009).

Several genetic variants of the genes encoding the cannabis receptor type 1 (CNR1) and FAAH have been identified (Monteleone et al., 2010). CNR1 has been localized to chromosome 6q14-q15 (Hoehe et al., 1991; Zhang et al., 2004). It has been suggested that genetic variability affecting ECS functionality can influence the individual susceptibility to mood disorders (Monteleone et al., 2010). Accordingly, the AAT triplet repeat polymorphism of the CNR1 gene, and different single nucleotide polymorphism (SNPs) of CNR1 and FAAH genes have been associated with depressive symptoms and with major depression (Barrero et al., 2005; Domschke et al., 2008). In major depression, SNPs of the CNR1 may also influence the response to antidepressant treatment (Domschke et al., 2008; Mitjans et al., 2013). Moreover, it has been evidenced that CNR1 SNPs may interact with previous negative experiences increasing the susceptibility to depression (Juhasz et al., 2009). In particular, in patients with major depression, CNR1 SNPs may affect responsiveness of subcortical structures, including the amygdala and striatum, to social rewarding stimuli (Domschke et al., 2008).

Overall, data from animal models and clinical studies suggest that the ECS functionality could influence anxiety and depression. The mechanisms underlying the interaction between ECS and mood are different and include the modulation of activity in limbic areas involved in reward processing, regulation of other neurotransmitters (i.e., noradrenaline, NA; DA; 5-HT), and HPA activation in the stress response (Hill and Patel, 2013; Micale et al., 2013).

\section{The ECS Mediates Reward}

Mesocorticolimbic DA projections to the limbic system, including the amygdala, hippocampus and orbitofrontal cortex (OFC), are critically involved in mediating reward (Koob and Volkow, 2010). In addition to DA other neurotransmitter, including acetylcholine, opiate peptides, glutamate and GABA, are involved in reward.

The ECS could modulate synaptic transmission in each of the abovementioned brain structures (Sidhpura and Parsons, 2011; Panagis et al., 2014), mediating the hedonic effects of different environmental rewarding stimuli (Trezza et al., 2010; Klein et al., 2012; Silvestri and Di Marzo, 2013). Accordingly, it has been evidenced that in CB1R-KO mice and after blockade of CB1R the rewarding effects of cannabinoids (Ledent et al., 1999), opiates (Ledent et al., 1999; Martin et al., 2000; Cossu et al., 2001), and cocaine (Chaperon et al., 1998) were reduced. Conversely, stimulation of CB1R was associated with relapses of substances abuse (Fattore et al., 2007; Higuera-Matas et al., 2008).

Experimental studies demonstrated that sensitization of CB1R-mediated transmission in the striatum may represent the neurophysiological hallmark of different forms of reward-based behavior. In mice, 1-day treatment with cocaine did not modify the synaptic response to CB agonists in the striatum. Conversely, 7 days of cocaine administration induced conditioned place preference, which is associated with hypersensitivity of striatal 
GABA synapses to the stimulation of CB1Rs (Centonze et al., 2007). Other environmental rewards were also associated with modulation of striatal DA (Mark et al., 1991; Hajnal et al., 2004; El Rawas et al., 2009), and were associated with upregulation of CB transmission in GABAergic striatal terminals (De Chiara et al., 2010). Accordingly, CB1R blockade reduces motivation for sweet foods, whereas activation of these receptors increases it (Simiand et al., 1998; Cota et al., 2003; Ward and Dykstra, 2005; Mahler et al., 2007).

The ECS may affect reward processing also in humans. Indeed, post-mortem studies evidenced altered expression of different ECS components in the prefrontal cortex of subject with alcohol abuse (Erdozain et al., 2014), moreover, reduced CB1R binding has been evidenced in vivo in patients with alcohol dependence (Hirvonen et al., 2013). In addition, SNPs of the CNR1 gene have been associated with drug misuse, alcohol withdrawal, and susceptibility to mood disorders (Barrero et al., 2005; Chen et al., 2008; Domschke et al., 2008; Marcos et al., 2012). In addition, also FAAH SNPs has been correlated to the risk of cannabis and alcohol abuse (Tyndale et al., 2007; Bühler et al., 2014). This evidence suggests that genetic variability in the ECS may influence reward sensitivity, and increase the risk of substance misuse (Parsons and Hurd, 2015).

\section{ECS and Stress}

Activation of the hypothalamic-pituitary-adrenal (HPA) axis represents the typical response to stress. While the HPA axis activity could be modulated by the ECS, conversely both stress and glucocorticoids could induce eCBs signaling in brain areas critically involved in behavioral responses, such as the hypothalamus and the amygdala (Hill and McEwen, 2010; Hill and Patel, 2013).

Experimental data suggest that the ECS could be crucially involved in mediating the neurophysiological and behavioral consequences of stress. In fact, stressful events may increase the synthesis of eCBs in the periaqueductal gray (Hohmann et al., 2005) and alter eCBs amount in brain areas associated with reward processing (Patel et al., 2005; Rademacher et al., 2008) thus modulating different responses, including stressinduced analgesia (Hohmann et al., 2005) and sensitivity to natural reward (Rademacher and Hillard, 2007). Notably, other neurotransmitter systems, including cholecystokinin signaling, are involved in the regulation of the behavioral consequences of stress (Kurrikoff et al., 2008).

It has been demonstrated that the behavioral effects of social stress in mice were associated with a selective alteration of the sensitivity of GABA synapses to CB1R activation. In particular, exposure to social stress in mice altered the CB1R-mediated control of GABAergic synaptic transmission in the striatum (Rossi et al., 2008). The specific role of stress is confirmed by the evidence that striatal synaptic alterations are prevented by glucocorticoid receptors blockade and reproduced by glucocorticoids administration. Finally, stress-induced synaptic alterations were rescued after either exposure to natural rewards (i.e., running wheel, sucrose) or administration of cocaine (Rossi et al., 2008). These data suggest that the ECS integrates different environmental stimuli, modulating their effects on striatal synaptic transmission. Notably, different types of rewards administered before the exposure to stress, may exert a protective effect against stress-induced synaptic alterations (De Chiara et al., 2010). In addition, human studies showed that ECS functionality could influence the response to stress (Neumeister et al., 2013; Pietrzak et al., 2014). In particular, different SNPs of the ECS have been associated to post-traumatic stress disorder (PTSD), influencing the effects of previous stressful events (Lu et al., 2008; Agrawal et al., 2012; Mota et al., 2015).

\section{INFLAMMATION AND MOOD}

Recent research has highlighted the relationship between the immune response and mood disturbances. In different inflammatory conditions, proinflammatory mediators could induce anxiety, anhedonia, social withdrawal, fatigue, and sleep disturbances, defined as "sickness behavior" (Raison et al., 2006; Dantzer et al., 2008; Miller et al., 2009). Accordingly, systemic administration of proinflammatory agents is able to promote the activation of microglial cells in the hippocampus and stimulate the release of proinflammatory cytokines in the CNS (van Dam et al., 1992; Breder et al., 1994; Layé et al., 1994; Riazi et al., 2008), and is associated with depression and anxiety (Reichenberg et al., 2001; Miller et al., 2009). Different inflammatory molecules, including interleukin (IL)-1 $\beta$ and tumor necrosis factor (TNF), have been implicated in the behavioral manifestations. In particular, central administration of these cytokines induces sickness behavior in animals (Dantzer et al., 2008; Haji et al., 2012; Rossi et al., 2012).

In addition, it has been proposed that inflammation may be implicated in the pathophysiology of different psychiatric syndromes, including major depression (Maes et al., 1995; Capuron et al., 2002). Accordingly, elevated biomarkers of systemic inflammation, as C-reactive protein, have been associated with depressive symptoms (Morris et al., 2011). It has been evidenced that depressed patients show higher peripheral blood levels of proinflammatory cytokines (Zorrilla et al., 2001; Dowlati et al., 2010; Haapakoski et al., 2015), and elevated inflammatory markers predict reduced response to antidepressant treatment (Strawbridge et al., 2015). Accordingly, increased prevalence of depression has been observed in patients with autoimmune disorders (Zeher et al., 2010), and blocking cytokine signaling can exert beneficial effects on mood (Tyring et al., 2006). Moreover, post-mortem studies in patients with major depression evidenced that also the innate immune response is altered, possibly contributing to the pathogenesis of depression (Martín-Hernández et al., 2018). Finally, it has been suggested that also the efficacy of different psychoactive treatments may be mediated by immunomodulatory properties (Maes et al., 1999; Cattaneo et al., 2013; Horowitz et al., 2015).

The effects of neuroinflammation on mood have been extensively investigated in neurological diseases and particularly in multiple sclerosis (MS). Anxiety and depression, are more frequent in MS patients compared to both general population (Patten et al., 2003) and other neurological patients (Schiffer and Babigian, 1984; Schubert and Foliart, 1993; Thielscher et al., 
2013). In particular, mood disturbances may be independent of other neurological deficits and may occur as a presenting symptom (Haussleiter et al., 2009; Lo Fermo et al., 2010; Suh et al., 2010). It has been shown that in animal models of MS (i.e., experimental autoimmune encephalomyelitis, EAE) sickness behavior is observed during the acute phase before the onset of motor signs (Pollak et al., 2000) and comes from altered neuronal activity produced by the inflammatory milieu (Gentile et al., 2015a).

Experimental studies showed that in EAE specific proinflammatory cytokines, particularly TNF and IL-1 $\beta$, are critically involved in the induction of mood alterations (Pollak et al., 2003; Gentile et al., 2015b). Notably, the synaptic alterations have been found in the striatum, a key structure involved in mood regulation both in rodents and humans (Mathew and Ho, 2006; Nestler and Carlezon, 2006; Kim et al., 2008; Zhang et al., 2008). In particular, striatal synaptic degeneration and dendritic spine loss have been found already during the early phases of EAE, independently of demyelination or clinical disability (Centonze et al., 2009). This data suggest that TNF-induced striatal synaptic dysfunction may be responsible of the behavioral manifestations. In line with these findings, intracerebroventricular injection of TNF in control mice was associated with anxious behavior (Haji et al., 2012). Conversely, intracerebroventricular administration of etanercept, a TNF inhibitor, reduced anxious behavior and prevented the synaptic alteration in EAE mice (Haji et al., 2012). In addition, elevated levels of IL-1 $\beta$ and IL-1 $\beta$ mRNA have been evidenced in the striatum of EAE mice, together with reduced dopaminergic transmission (Gentile et al., 2015b). Accordingly, blocking IL-1 $\beta$ signaling in EAE mice can reduce mood alterations and restore DA release in the striatum (Gentile et al., 2015b).

\section{Inflammation and ECS}

A complex bidirectional interaction exists between the ECS and the immune system. eCBs signaling has immunosuppressant actions, in particular, CB2R stimulation reduce both inflammation (Pandey et al., 2009) and circulating proinflammatory mediators (Croxford and Miller, 2003). Conversely, lipopolysaccharide administration modulates eCB signaling (Klein et al., 2003). In particular, microglial cells are recently emerging as key elements mediating the relationship between inflammation and the ECS. Microglia express CBRs, particularly CB2Rs, and is able to release both inflammatory mediators and eCBs (Stella, 2009; Boorman et al., 2016). Notably, CB2R stimulation in microglial cells promote the release of anti-inflammatory cytokines (Ma et al., 2015). Therefore, reduced $\mathrm{CB} 2 \mathrm{R}$ stimulation may contribute to the pathogenesis of mood disorders. Accordingly, it has been evidenced that a polymorphism of the $\mathrm{CB} 2 \mathrm{R}$ gene, producing reduced activation of the $\mathrm{CB} 2 \mathrm{R}$ receptor, was associated with increased incidence of depression (Onaivi et al., 2008). Moreover, it has been demonstrated that treatment with both minocycline and antidepressant drugs was associated to reduced release of proinflammatory molecules by microglial cells (Burke et al., 2014; Su et al., 2015).
Several studies evidenced that the ECS plays a critical role in mediating the effects of inflammation on synaptic functioning and mood. Accordingly, in EAE mice, CB1Rs stimulation may counteract the TNF-mediated synaptic alterations (Rossi et al., 2011). In particular, administration of a CB1R agonist, prevented the alterations of striatal transmission produced by TNF on brain slices.

Several evidences suggest that specific proinflammatory mediators, including IL-1 $\beta$ and IFNr, modulate striatal CB1R sensitivity (Rossi et al., 2012; Gentile et al., 2016; Mandolesi et al., 2017). In particular, intracerebroventricular administration of IL$1 \beta$ in control mice induced anxious behavior and was associated with reduced sensitivity of striatal GABAergic synapses to CB1Rs stimulation (Rossi et al., 2012). It has been observed that IL-1 $\beta$ mediates the effects of inflammation in EAE mice (Gentile et al., 2016). Accordingly, blocking IL-1 $\beta$ signaling restored striatal CB1Rs sensitivity and reduced anxious behavior (Gentile et al., 2016).

Interestingly, it has been shown that inflammatory signals and environmental stimuli interact with the ECS to produce mood changes. In particular, the effects of IL-1 $\beta$ administration on striatal transmission were similar to the alterations induced by social defeat stress (Rossi et al., 2008). Furthermore, administration of IL- $1 \beta$ receptor antagonist (IL-1ra) was able to revert the synaptic and behavioral effects induced by both IL-1 $\beta$ injection and social defeat stress. These results suggest that IL-1 $\beta$ is involved in inflammation-induced mood alterations and also play a key role in mediating responses to environmental stress (Koo and Duman, 2008; Goshen and Yirmiya, 2009; Norman et al., 2010).

\section{THERAPEUTIC APPLICATION OF CANNABINOIDS}

Cannabis contains numerous active components. In particular, $\triangle 9$-tetrahydrocannabinol (THC) and cannabidiol (CBD) represent the main phytocannabinoids (Huestis, 2007). In addition to smoked cannabis, different commercially available compounds have been produced (i.e., dronabinol, nabilone, Sativex ${ }^{\circledR}$ ), differing in THC and CBD composition. Cannabisderived treatments are currently approved for several clinical conditions, including spasticity, pain, nausea, and some epileptic conditions (Pacher and Kunos, 2013; Devinsky et al., 2014). However, despite numerous reports of beneficial effects on anxiety and depression, the clinical efficacy is still debated (Whiting et al., 2015; Turna et al., 2017). In particular, recent reviews and meta-analyses, concluded that evidence supporting clinical benefits of cannabis-based therapies in mood disorders is scarce, and limited to low-grade evidence supporting the beneficial effect of CBD in social anxiety (Bergamaschi et al., 2011) and of medical marijuana in PTSD (Walsh et al., 2017).

The limited approved clinical indications contrast with the ample evidence, derived by preclinical studies and also from anecdotal observations, showing beneficial effects of ECS modulation on mood. It should be considered that a number of factors may contribute to the lack of clear findings. It has 
been observed that most clinical studies were considered as at high risk of bias, generally for incomplete report of outcome measures and for inadequate blinding procedure (Whiting et al., 2015). In addition, clinical studies mainly explored the effects of synthetic principles, and studies exploring the effects of cannabis are limited. Furthermore, the role of genetic individual variability should be considered, as differences in CB1Rs sensitivity to phytocannabinoids may explain the ample variability of the effects reported by patients.

A specific confounding factor that limits the clinical evidences supporting the beneficial effects of cannabinoids on mood is the difficulty in controlling the placebo effect. It is worth noting that the placebo response could significantly influence the clinical effect of drugs acting on the ECS (Benedetti et al., 2011a; Di Marzo and Centonze, 2015). Placebo effect constitutes a complex phenomenon coming from both the social ritual represented by placebo administration and the psychosocial context (Benedetti et al., 2011a). Interestingly, it has been clearly demonstrated that both the placebo response and drugs activate the same biochemical pathways. In particular, the placebo analgesia is mediated by both the opioid system and the ECS (Wager et al., 2007; Benedetti et al., 2011b). Consequently, it has been demonstrated that the administration of rimonabant inhibits the non-opioid placebo response (Benedetti et al., 2011b). In clinical trials evaluating the efficacy of antidepressant medications, it has been shown that the placebo effect could be responsible for at least one-half of the beneficial effect (Kirsch and Sapirstein, 1998) representing a relevant confounding factor. Indeed, as ECS mediates both the antidepressant effect of drugs and the placebo response, patients responding to antidepressant drugs may also show a marked placebo response.

Finally, concerns about the risks associated to cannabis use have limited the clinical indications of medical marijuana. In particular, acute cannabis use has also been associated with worsening of anxiety (Crippa et al., 2009). Furthermore, it has been proposed that chronic consumption could be associated

\section{REFERENCES}

Adamczyk, P., Gołda, A., McCreary, A. C., Filip, M., and Przegalinski, E. (2008). Activation of endocannabinoid transmission induces antidepressant-like effects in rats. J. Physiol. Pharmacol. 59, 217-228.

Agrawal, A., Nelson, E. C., Littlefield, A. K., Bucholz, K. K., Degenhardt, L., Henders, A. K., et al. (2012). Cannabinoid receptor (CNR1) genotype moderates the effects of childhood physical abuse on anhedonia and depression. Arch. Gen. Psychiatry 69, 732-740. doi: 10.1001/archgenpsychiatry.2011.2273

Alger, B. E. (2002). Retrograde signaling in the regulation of synaptic transmission: focus on endocannabinoids. Prog. Neurobiol. 68, 247-286. doi: 10.1016/S0301-0082(02)00080-1

Barrero, F. J., Ampuero, I., Morales, B., Vives, F., de Dios Luna Del Castillo, J., Hoenicka, J., et al. (2005). Depression in Parkinson's disease is related to a genetic polymorphism of the cannabinoid receptor gene (CNR1). Pharmacogenom. J. 5, 135-141. doi: 10.1038/sj.tpj.6500301

Benedetti, F., Amanzio, M., Rosato, R., and Blanchard, C. (2011b). Nonopioid placebo analgesia is mediated by CB1 cannabinoid receptors. Nat. Med. 17, 1228-1230. doi: $10.1038 / \mathrm{nm} .2435$ with increased risk of psychosis, cognitive impairment and addictiveness in predisposed subjects (Volkow et al., 2014; Ksir and Hart, 2016; Turna et al., 2017).

\section{CONCLUSIONS}

Emotional homeostasis is crucially modulated by the activity of the ECS. In particular, different environmental and endogenous stimuli could influence the emotional state by modulating the sensitivity to eCBs of different neurotransmitter pathways in multiple brain areas. Cannabis-based compounds could exert antidepressant effects through complex influences on different behavioral responses, such as those associated to reward, stress and inflammation, also depending on the individual psychosocial context. Overall, these issues make it difficult to demonstrate unequivocal relationships between ECS modulation and the effects on mood. Although targeting the ECS could represent a promising treatment option in different psychiatric conditions, future clinical trials should be designed to explore specific outcome measures, to reduce the individual variability and to consider the placebo response. In the last years, the ample diffusion of smoked or vaporized cannabis for recreational and therapeutic purposes has not been accompanied by measures aimed at promoting information about medical marijuana use. In this view, it is important to design specific interventions to overcome the gap between preclinical studies and clinical evidences on the potential therapeutic use of cannabinoids.

\section{AUTHOR CONTRIBUTIONS}

MS and EI: work conception and design, drafting the work, work revision, final approval, and global agreement. LG: work conception and design, work revision, final approval, and global agreement. PM, ED, AB, and FB: work revision, final approval, and global agreement. DC: work conception and design, guarantor of integrity of entire study, manuscript revision for important intellectual content, final approval.

Benedetti, F., Carlino, E., and Pollo, A. (2011a). How placebos change the patient's brain. Neuropsychopharmacology. 36, 339-354. doi: 10.1038/npp.2010.81

Bergamaschi, M. M., Queiroz, R. H., Zuardi, A. W., and Crippa, J. A. (2011). Safety and side effects of cannabidiol, a Cannabis sativa constituent. Curr. Drug Saf. 6, 237-249. doi: 10.2174/157488611798280924

Boorman, E., Zajkowska, Z., Ahmed, R., Pariante, C. M., and Zunszain, P. A. (2016). Crosstalk between endocannabinoid and immune systems: a potential dysregulation in depression? Psychopharmacology 233, 1591-1604. doi: 10.1007/s00213-015-4105-9

Breder, C. D., Hazuka, C., Ghayur, T., Klug, C., Huginin, M., Yasuda, K., et al. (1994). Regional induction of tumor necrosis factor alpha expression in the mouse brain after systemic lipopolysaccharide administration. Proc. Natl. Acad. Sci. U.S.A. 91, 11393-11397. doi: 10.1073/pnas.91.24. 11393

Bühler, K. M., Huertas, E., Echeverry-Alzate, V., Ginè, E., Moltó, E., Montoliu, L., et al. (2014). Risky alcohol consumption in young people is associated with the fatty acid amide hydrolase gene polymorphism C385A and affective rating of drug pictures. Mol. Genet. Genomics. 289, 279-289. doi: 10.1007/s00438-013-0809-x 
Burke, N. N., Kerr, D. M., Moriarty, O., Finn, D. P., and Roche, M. (2014). Minocycline modulates neuropathic pain behaviour and cortical M1-M2 microglial gene expression in a rat model of depression. Brain Behav. Immun. 42, 147-156. doi: 10.1016/j.bbi.2014.06.015

Capuron, L., Hauser, P., Hinze-Selch, D., Miller, A. H., and Neveu, P. J. (2002). Treatment of cytokine-induced depression. Brain Behav. Immun. 16, 575-580. doi: 10.1016/S0889-1591(02)00007-7

Castillo, P. E., Younts, T. J., Chávez, A. E., and Hashimotodani, Y. (2012). Endocannabinoid signaling and synaptic function. Neuron 76, 70-81. doi: 10.1016/j.neuron.2012.09.020

Cattaneo, A., Gennarelli, M., Uher, R., Breen, G., Farmer, A., Aitchison, K. J., et al. (2013). Candidate genes expression profile associated with antidepressants response in the GENDEP study: differentiating between baseline 'predictors' and longitudinal 'targets'. Neuropsychopharmacology 38, 377-385. doi: 10.1038/npp.2012.191

Centonze, D., Muzio, L., Rossi, S., Cavasinni, F., De Chiara, V., Bergami, A., et al. (2009). Inflammation triggers synaptic alteration and degeneration in experimental autoimmune encephalomyelitis. J. Neurosci. 29, 3442-3452. doi: 10.1523/JNEUROSCI.5804-08.2009

Centonze, D., Rossi, S., De Chiara, V., Prosperetti, C., Battista, N., Bernardi, G., et al. (2007). Chronic cocaine sensitizes striatal GABAergic synapses to the stimulation of cannabinoid CB1 receptors. Eur. J. Neurosci. 25, 1631-1640. doi: 10.1111/j.1460-9568.2007.05433.x

Chaperon, F., Soubrié, P., Puech, A. J., and Thiébot, M. H. (1998). Involvement of central cannabinoid (CB1) receptors in the establishment of place conditioning in rats. Psychopharmacology 135, 324-332.

Chen, X., Williamson, V. S., An, S.-S., Hettema, J. M., Aggen, S. H., Neale, M. C., et al. (2008). Cannabinoid receptor 1 gene association with nicotine dependence. Arch. Gen. Psychiatry 65, 816-824. doi: 10.1001/archpsyc.65.7.816

Chiang, N., Dalli, J., Colas, R. A., and Serhan, C. N. (2015). Identification of resolvin D2 receptor mediating resolution of infections and organ protection. J. Exp. Med. 212, 1203-1217. doi: 10.1084/jem.20150225

Cossu, G., Ledent, C., Fattore, L., Imperato, A., Bohme, G. A., Parmentier, M., et al. (2001). Cannabinoid CB1 receptor knockout mice fail to selfadminister morphine but not other drugs of abuse. Behav. Brain. Res. 118, 61-65. doi: 10.1016/S0166-4328(00)00311-9

Cota, D., Marsicano, G., Lutz, B., Vicennati, V., Stalla, G. K., Pasquali, R., et al. (2003). Endogenous cannabinoid system as a modulator of food intake. Int. J. Obes. Relat. Metab. Disord. 27, 289-301. doi: 10.1038/sj.ijo.802250

Crippa, J. A., Zuardi, A. W., Martín-Santos, R., Bhattacharyya, S., Atakan, Z., McGuire, P., et al. (2009). Cannabis and anxiety: a critical review of the evidence. Hum. Psychopharmacol. 24, 515-523. doi: 10.1002/hup.1048

Croxford, J. L., and Miller, S. D. (2003). Immunoregulation of a viral model of multiple sclerosis using the synthetic cannabinoid R+WIN55,212. Clin Invest. 111, 1231-1240. doi: 10.1172/JCI17652

Dantzer, R., O’Connor, J. C., Freund, G. G., Johnson, R. W., and Kelley, K. W. (2008). From inflammation to sickness and depression: when the immune system subjugates the brain. Nat. Rev. Neurosci. 9, 46-56. doi: 10.1038/nrn2297

De Chiara, V., Errico, F., Musella, A., Rossi, S., Mataluni, G., Sacchetti, L., et al. (2010). Voluntary exercise and sucrose consumption enhance cannabinoid CB1 receptor sensitivity in the striatum. Neuropsychopharmacology 35, 374-387. doi: $10.1038 / \mathrm{npp} .2009 .141$

Després, J. P., Golay, A., and Sjöström, L., for the Rimonabant in ObesityLipids Study Group. (2005). Effects of rimonabant on metabolic risk factors in overweight patients with dyslipidemia. N. Engl. J. Med. 353, 2121-2134. doi: 10.1056/NEJMoa04453

Devinsky, O., Cilio, M. R., Cross, H., Fernandez-Ruiz, J., French, J., Hill, C., et al. (2014). Cannabidiol: pharmacology and potential therapeutic role in epilepsy and other neuropsychiatric disorders. Epilepsia 55, 791-802. doi: $10.1111 /$ epi.12631

Di Marzo, V. (2009). The endocannabinoid system: its general strategy of action, tools for its pharmacological manipulation and potential therapeutic exploitation. Pharmacol. Res. 60, 77-84. doi: 10.1016/j.phrs.2009.02.010

Di Marzo, V., and Centonze, D. (2015). Placebo effects in a multiple sclerosis spasticity enriched clinical trial with the oromucosal cannabinoid spray (THC/CBD): dimension and possible causes. CNS Neurosci Ther. 21, 215-221. doi: $10.1111 / \mathrm{cns} .12358$
Di Marzo, V., Melck, D., Bisogno, T., and De Petrocellis, L. (1998). Endocannabinoids: endogenous cannabinoid receptor ligands with neuromodulatory action. Trends Neurosci. 21, 521-528. doi: 10.1016/S0166-2236(98)01283-1

Domschke, K., Dannlowski, U., Ohrmann, P., Lawford, B., Bauer, J., Kugel, H., et al. (2008). Cannabinoid receptor 1 (CNR1) gene: impact on antidepressant treatment response and emotion processing in major depression. Eur. Neuropsychopharmacol. 18, 751-759. doi: 10.1016/j.euroneuro.2008.05.003

Dowlati, Y., Herrmann, N., Swardfager, W., Liu, H., Sham, L., Reim, E. K., et al. (2010). A meta-analysis of cytokines in major depression. Biol. Psichiatry 67, 446-457. doi: 10.1016/j.biopsych.2009.09.033

El Rawas, R., Thiriet, N., Lardeux, V., Jaber, M., and Solinas, M. (2009). Environmental enrichment decreases the rewarding but not the activating effects of heroin. Psychopharmacology 203, 561-570. doi: 10.1007/s00213-008-1402-6

Erdozain, A. M., Rubio, M., Valdizan, E. M., Pazos, A., Meana, J. J., FernándezRuiz, J., et al. (2014). The endocannabinoid system is altered in the postmortem prefrontal cortex of alcoholic subjects. Addict. Biol. 20, 773-783. doi: $10.1111 / \mathrm{adb} .12160$

Farran, B. (2017). An update on the physiological and therapeutic relevance of GPCR oligomers. Pharmacol. Res. 117, 303-327. doi: 10.1016/j.phrs.2017.01.008

Fattore, L., Spano, M. S., Deiana, S., Melis, V., Cossu, G., Fadda, P., et al. (2007). An endocannabinoid mechanism in relapse to drug seeking: a review of animal studies and clinical perspectives. Brain Res. Rev. 53, 1-16. doi: 10.1016/j.brainresrev.2006.05.003

Gentile, A., De Vito, F., Fresegna, D., Musella, A., Buttari, F., Bullitta, S., et al. (2015a). Exploring the role of microglia in mood disorders associated with experimental multiple sclerosis. Front. Cell. Neurosci. 9:243. doi: $10.3389 /$ fncel.2015.00243

Gentile, A., Fresegna, D., Federici, M., Musella, A., Rizzo, F. R., Sepman, H., et al. (2015b). Dopaminergic dysfunction is associated with IL-1 $\beta$-dependent mood alterations in experimental autoimmune encephalomyelitis. Neurobiol. Dis. 74, 347-358. doi: 10.1016/j.nbd.2014.11.022

Gentile, A., Fresegna, D., Musella, A., Sepman, H., Bullitta, S., De Vito, F., et al. (2016). Interaction between interleukin-1 $\beta$ and type1 cannabinoid receptor is involved in anxiety-like behavior in experimental autoimmune encephalomyelitis. J. Neuroinflammation 13, 231. doi: 10.1186/s12974-016-0682-8.

Glass, M., Dragunow, M., and Faull, R. L. (1997). Cannabinoid receptors in the human brain: a detailed anatomical and quantitative autoradiographic study in the fetal, neonatal and adult human brain. Neuroscience 77, 299-318. doi: 10.1016/S0306-4522(96)00428-9

Gobbi, G., Bambico, F. R., Mangieri, R., Bortolato, M., Campolongo, P., Solinas, M., et al. (2005). Antidepressant-like activity and modulation of brain monoaminergic transmission by blockade of anandamide hydrolysis. Proc. Natl. Acad. Sci. U.S.A. 102, 18620-18625. doi: 10.1073/pnas.0509591102

Goshen, I., and Yirmiya, R. (2009). Interleukin-1 (IL-1): a central regulator of stress responses. Front. Neuroendocrinol. 30, 30-45. doi: 10.1016/j.yfrne.2008. 10.001

Haapakoski, R., Mathieu, J., Ebmeier, K. P., Alenius, H., and Kivimäki, M. (2015). Cumulative meta-analysis of interleukins 6 and $1 \beta$, tumour necrosis factor $\alpha$ and C-reactive protein in patients with major depressive disorder. Brain Behav. Immun. 49, 206-215. doi: 10.1016/j.bbi.2015.06.001

Haji, N., Mandolesi, G., Gentile, A., Sacchetti, L., Fresegna, D., Rossi, S., et al. (2012). TNF- $\alpha$-mediated anxiety in a mouse model of multiple sclerosis. Exp. Neurol. 237, 296-303. doi: 10.1016/j.expneurol.2012.07.010

Hajnal, A., Smith, G. P., and Norgren, R. (2004). Oral sucrose stimulation increases accumbens dopamine in the rat. Am. J. Physiol. Regul. Integr. Comp. Physiol. 286, 31-37. doi: 10.1152/ajpregu.00282.2003

Haller, J., Varga, B., Ledent, C., and Freund, T. F. (2004). CB1 cannabinoid receptors mediate anxiolytic effects: convergent genetic and pharmacological evidence with CB1-specific agents. Behav. Pharmacol. 15, 299-304. doi: 10.1097/01.fbp.0000135704.56422.40

Haussleiter, I. S., Brüne, M., and Juckel, G. (2009). Review: Psychopathology in multiple sclerosis: diagnosis, prevalence and treatment. Ther. Adv. Neurol. Disord. 2, 13-29. doi: 10.1177/1756285608100325 
Heifets, B. D., and Castillo, P. E. (2009). Endocannabinoid signaling and long-term synaptic plasticity. Ann. Rev. Physiol. 71, 283-306. doi: 10.1146/annurev.physiol.010908.163149

Heinbockel, T., Brager, D. H., Reich, C. G., Zhao, J., Muralidharan, S., Alger, B. E., et al. (2005). Endocannabinoid signaling dynamics probed with optical tools. J. Neurosci. 25, 9449-9459. doi: 10.1523/JNEUROSCI.2078-05.2005

Herkenham, M., Lynn, A. B., Johnson, M. R., Melvin, L. S., de Costa, B. R., and Rice, K. C. (1991). Characterization and localization of cannabinoid receptors in rat brain: a quantitative in vitro autoradiographic study. J. Neurosci. 11, 563-583. doi: 10.1523/JNEUROSCI.11-02-00563.1991

Higuera-Matas, A., Soto-Montenegro, M. L., Del Olmo, N., Miguens, M., Torres, I., Vaquero, J. J., et al. (2008). Augmented acquisition of cocaine self-administration and altered brain glucose metabolism in adult female but not male rats exposed to a cannabinoid agonist during adolescence. Neuropsychopharmacology 33, 806-813. doi: 10.1038/sj.npp.1301467

Hill, M. N., and Gorzalka, B. B. (2005a). Is there a role for the endocannabinoid system in the etiology and treatment of melancholic depression? Behav. Pharmacol. 16, 333-352.

Hill, M. N., and Gorzalka, B. B. (2005b). Pharmacological enhancement of cannabinoid $\mathrm{CB} 1$ receptor activity elicits an antidepressant-like response in the rat forced swim test. Eur. Neuropsychopharmacol. 15, 593-599. doi: 10.1016/j.euroneuro.2005.03.003

Hill, M. N., Hillard, C. J., Bambico, F. R., Patel, S., Gorzalka, B. B., and Gobbi, G. (2009a). The therapeutic potential of the endocannabinoid system for the development of a novel class of antidepressants. Trends Pharmacol. Sci. 30, 484-493. doi: 10.1016/j.tips.2009.06.006

Hill, M. N., Ho, W. S., Sinopoli, K. J., Viau, V., Hillard, C. J., and Gorzalka, B. B. (2006). Involvement of the endocannabinoid system in the ability of longterm tricyclic antidepressant treatment to suppress stress-induced activation of the hypothalamic-pituitary-adrenal axis. Neuropsychopharmacology 31, 2591-2599. doi: 10.1038/sj.npp.1301092

Hill, M. N., and McEwen, B. S. (2010). Involvement of the endocannabinoid system in the neurobehavioural effects of stress and glucocorticoids. Prog. Neuropsychopharmacol. Biol. Psychiatry 34, 791-797. doi: 10.1016/j.pnpbp.2009.11.001

Hill, M. N., Miller, G. E., Carrier, E. J., Gorzalka, B. B., and Hillard, C. J. (2009b). Circulating endocannabinoids and $\mathrm{N}$-acyl ethanolamines are differentially regulated in major depression and following exposure to social stress. Psychoneuroendocrinology 34, 1257-1262. doi: 10.1016/j.psyneuen.2009.03.013

Hill, M. N., Miller, G. E., Ho, W. S., Gorzalka, B. B., and Hillard, C. J. (2008). Serum endocannabinoid content is altered in females with depressive disorders: a preliminary report. Pharmacopsychiatry 41, 48-53. doi: 10.1055/s-2007-993211

Hill, M. N., and Patel, S. (2013). Translational evidence for the involvement of the endocannabinoid system in stress-related psychiatric illnesses. Biol. Mood Anxiety Disord. 3, 1-19. doi: 10.1186/2045-5380-3-19

Hirvonen, J., Zanotti-Fregonara, P., Umhau, J. C., George, D. T., Rallis-Frutos, D., Lyoo, C. H. et al. (2013). Reduced cannabinoid CB1 receptor binding in alcohol dependence measured with positron emission tomography. Mol. Psychiatry 18, 916-921. doi: 10.1038/mp.2012.100

Hoehe, M. R., Caenazzo, L., Martinez, M. M., Hsieh, W. T., Modi, W. S., Gershon, E. S., et al. (1991). Genetic and physical mapping of the human cannabinoid receptor gene to chromosome 6q14-q15. New Biol. 3, 880-885.

Hohmann, A. G., Suplita, R. L., Bolton, N. M., Neely, M. H., Fegley, D., Mangieri, R., et al. (2005). An endocannabinoid mechanism for stress-induced analgesia. Nature 435, 1108-1112. doi: 10.1038/nature03658

Horowitz, M. A., Wertz, J., Zhu, D., Cattaneo, A., Musaelyan, K., Nikkheslat, N., et al. (2015). Antidepressant compounds can be both pro- and antiinflammatory in human hippocampal cells. Int. J. Neuropsychopharmacol. 18, 3. doi: 10.1093/ijnp/pyu076.

Howlett, A. C., Barth, F., Bonner, T. I., Cabral, G., Casellas, W. A., Devane, C. C., et al. (2002). International Union of Pharmacology. XXVII. Classification of cannabinoid receptors. Pharmacol. Rev. 54, 161-202. doi: 10.1124/pr.54.2.161

Huestis, M. A. (2007). Human cannabinoid pharmacokinetics. Chem. Biodivers. 4, 1770-1804. doi: 10.1002/cbdv.200790152

Juhasz, G., Chase, D., Pegg, E., Downey, D., Toth, Z. G., Stones, K., et al. (2009). CNR1 gene is associated with high neuroticism and low agreeableness and interacts with recent negative life events to predict current depressive symptoms. Neuropsychopharmacology 34, 2019-2027. doi: 10.1038/npp.2009.19

Kano, M., Ohno-Shosaku, T., Hashimotodani, Y., Uchigashima, M., and Watanabe, M. (2009). Endocannabinoid-mediated control of synaptic transmission. Physiol. Rev. 89, 309-380. doi: 10.1152/physrev.00019.2008

Kathuria, S., Gaetani, S., Fegley, D., Valiño, F., Duranti, A., Tontini, A., et al. (2003). Modulation of anxiety through blockade of anandamide hydrolysis. Nat. Med. 9, 76-81. doi: 10.1038/nm803

Kim, K. S., Lee, K. W., Baek, I. S., Lim, C. M., Krishnan, V., Lee, J. K., et al. (2008). Adenylyl cyclase-5 activity in the nucleus accumbens regulates anxiety-related behavior. J. Neurochem. 107, 105-115. doi: 10.1111/j.1471-4159.2008.05592.x

Kirsch, I., and Sapirstein, G. (1998). Listening to Prozac but hearing placebo: a meta-analysis of antidepressant medication. Prevent. Treat. 1:2a. doi: $10.1037 / 1522-3736.1 .1 .12 \mathrm{a}$

Klein, C., Hill, M. N., Chang, S. C., Hillard, C. J., and Gorzalka, B. B. (2012). Circulating endocannabinoid concentrations and sexual arousal in women. $J$. Sex. Med. 9, 1588-1601. doi: 10.1111/j.1743-6109.2012.02708.x

Klein, T. W., Newton, C., Larsen, K., Lu, L., Perkins, I., Nong, L., et al. (2003). The cannabinoid system and immune modulation. J. Leukoc. Biol. 74, 486-496. doi: 10.1189/jlb.0303101

Koo, J. W., and Duman, R. S. (2008). IL-1beta is an essential mediator of the antineurogenic and anhedonic effects of stress. Proc. Natl. Acad. Sci. U.S.A. 105, 751-756. doi: 10.1073/pnas.0708092105

Koob, G. F., and Volkow, N. D. (2010). Neurocircuitry of addiction. Neuropsychopharmacology 35, 217-238. doi: 10.1038/npp.2009.110

Ksir, C., and Hart, C. L. (2016). Cannabis and psychosis: a critical overview of the relationship. Curr. Psychiatry Rep. 18, 12. doi: 10.1007/s11920-015-0657-y

Kurrikoff, K., Inno, J., Matsui, T., and Vasar, E. (2008). Stress-induced analgesia in mice: evidence for interaction between endocannabinoids and cholecystokinin. Eur. J. Neurosci. 27, 2147-2155. doi: 10.1111/j.1460-9568.2008.06160.x

Layé, S., Parnet, P., Goujon, E., and Dantzer, R. (1994). Peripheral administration of lipopolysaccharide induces the expression of cytokine transcripts in the brain and pituitary of mice. Mol. Brain Res. 27, 157-162. doi: 10.1016/0169-328X(94)90197-X

Ledent, C., Valverde, O., Cossu, G., Petitet, F., Aubert, J. F., Beslot, F., et al. (1999). Unresponsiveness to cannabinoids and reduced addictive effects of opiates in CB1 receptor knockout mice. Science 283, 401-404. doi: 10.1126/science.283.5400.401

Lo Fermo, S., Barone, R., Patti, F., Laisa, P., Cavallaro, T. L., Nicoletti, A., et al. (2010). Outcome of psychiatric symptoms presenting at onset of multiple sclerosis: a retrospective study. Mult. Scler. 16, 742-748. doi: 10. $1177 / 1352458510365157$

Lovinger, D. M. (2008). "Presynaptic modulation by endocannabinoids", in: Pharmacology of Neurotransmitter Release. Handbook of Experimental Pharmacology (Berlin: Springer, Heidelberg), 435-477.

Lu, A. T., Ogdie, M. N., Jarvelin, M.-R., Moilanem, I. K., Loo, S. K., McCracken, J. T., et al. (2008). Association of the cannabinoid receptor gene (CNR1) with ADHD and post-traumatic stress disorder. Am. J. Med. Genet. B Neuropsychiatr. Genet. 8, 1488-1494. doi: 10.1002/ajmg.b.30693

Lutz, B., Marsicano, G., Maldonado, R., and Hillard, C. J. (2015). The endocannabinoid system in guarding against fear, anxiety and stress. Nat. Rev. Neurosci. 16, 705-718. doi: 10.1038/nrn4036

Ma, L., Jia, J., Liu, X., Bai, F., Wang, Q., and Xiong, L. (2015). Activation of murine microglial N9 cells is attenuated through cannabinoid receptor CB2 signaling. Biochem. Biophys. Res. Commun. 458, 92-97. doi: 10.1016/j.bbrc.2015.01.073

Maes, M., Meltzer, H. Y., Bosmans, E., Bergmans, R., Vandoolaeghe, E., Ranjan, R., et al. (1995). Increased plasma concentrations of interleukin-6, soluble interleukin-6, soluble interleukin-2 and transferrin receptor in major depression. J. Affect. Disord. 34, 301-309. doi: 10.1016/0165-0327(95)00028-L

Maes, M., Song, C., Lin, A.-H., Bonaccorso, S., Kenis, G., De Jongh, R., et al. (1999). Negative immunoregulatory effects of antidepressants: inhibition of interferongamma and stimulation of interleukin-10 secretion. Neuropsychopharmacology 20, 370-379. doi: 10.1016/S0893-133X(98)00088-8

Mahler, S. V., Smith, K. S., and Berridge, K. C. (2007). Endocannabinoid hedonic hotspot for sensory pleasure: anandamide in nucleus accumbens shell enhances 'liking' of a sweet reward. Neuropsychopharmacology 32, 2267-2278. doi: 10.1038/sj.npp.1301376 
Mandolesi, G., Bullitta, S., Fresegna, D., Gentile, A., De Vito, F., Dolcetti, E., et al. (2017). Interferon- $\gamma$ causes mood abnormalities by altering cannabinoid CB1 receptor function in the mouse striatum. Neurobiol. Dis. 108, 45-53. doi: 10.1016/j.nbd.2017.07.019.

Marcos, M., Pastor, I., de la Calle, C., Barrio-Real, L., Laso, F. J., and González-Sarmiento, R. (2012). Cannabinoid receptor 1 gene is associated with alcohol dependence. Alcohol. Clin. Exp. Res. 36, 267-271. doi: 10.1111/j.1530-0277.2011.01623.x

Mark, G. P., Blander, D. S., and Hoebel, B. G. (1991). A conditioned stimulus decreases extracellular dopamine in the nucleus accumbens after the development of a learned taste aversion. Brain Res. 551, 308-310. doi: 10.1016/0006-8993(91)90946-s

Martin, M., Ledent, C., Parmentier, M., Maldonado, R., and Valverde, O. (2000). Cocaine, but not morphine, induces conditioned place preference and sensitization to locomotor responses in CB1 knockout mice. Eur. J. Neurosci. 12, 4038-4046. doi: 10.1046/j.1460-9568.2000.00287.x

Martin, M., Ledent, C., Parmentier, M., Maldonado, R., and Valverde, O. (2002). Involvement of CB1 cannabinoid receptors in emotional behaviour. Psychopharmacology 159, 379-387. doi: 10.1007/s00213-001-0946-5

Martín-Hernández, D., Caso, J. R., Meana, J. J., Callado, L. F., Madrigal, J. L. M., García-Bueno, B., et al. (2018). Intracellular inflammatory and antioxidant pathways in postmortem frontal cortex of subjects with major depression: effect of antidepressants. J. Neuroinflammation 15, 251. doi: 10.1186/s12974-018-1294-2

Mathew, S. J., and Ho, S. (2006). Etiology and neurobiology of social anxiety disorder. J. Clin. Psychiatry 67, 9-13.

Micale, V., Di Marzo, V., Sulcova, A., Wotjak, C. T., and Drago, F. (2013). Endocannabinoid system and mood disorders: priming a target for new therapies. Pharmacol. Ther. 138, 18-37. doi: 10.1016/j.pharmthera.2012.12.002

Mikics, E., Vas, J., Aliczki, M., Halasz, J., and Haller, J. (2009). Interactions between the anxiogenic effects of CB1 gene disruption and 5-HT3 neurotransmission. Behav. Pharmacol. 20, 265-272. doi: 10.1097/FBP.0b013e32832c70b1

Miller, A. H., Maletic, V., and Raison, C. L. (2009). Inflammation and its discontents: the role of cytokines in the pathophysiology of major depression. Biol. Psychiatry 65, 732-741. doi: 10.1016/j.biopsych.2008.11.029

Mitjans, M., Serretti, A., Fabbri, C., Gastó, C., Catalán, R., Fañanás, L., et al. (2013). Screening genetic variability at the CNR1 gene in both major depression etiology and clinical response to citalopram treatment. Psychopharmacology 227, 509-519. doi: 10.1007/s00213-013-2995-y

Monteleone, P., Bifulco, M., Maina, G., Tortorella, A., Gazzerro, P., Proto, M. C., et al. (2010). Investigation of CNR1 and FAAH endocannabinoid gene polymorphisms in bipolar disorder and major depression. Pharmacol. Res. 61, 400-404. doi: 10.1016/j.phrs.2010.01.002

Morales, P., and Reggio, P. H. (2017). An Update on Non- $\mathrm{CB}_{1}$, Non- $\mathrm{CB}_{2}$ Cannabinoid Related G-Protein-Coupled Receptors. Cannabis Cannabinoid Res. 2, 265-273. doi: 10.1089/can.2017.0036

Morris, A. A., Zhao, L., Ahmed, Y., Stoyanova, N., De Staercke, C., Hooper, W. C., et al. (2011). Association between depression and inflammation-differences by race and sex: The META-Health Study. Psychosom. Med. 73, 462-468. doi: 10.1097/PSY.0b013e318222379c

Mota, N., Sumner, J. A., Lowe, S. R., Neumeister, A., Uddin, M., Aiello, A. E., et al. (2015). The rs1049353 polymorphism in the CNR1 gene interacts with childhood abuse to predict posttraumatic threat symptoms. J. Clin. Psychiatry 76, e1622-e1623. doi: 10.4088/JCP.15110084

Nakazi, M., Bauer, U., Nickel, T., Kathmann, M., and Schlickler, E. (2000). Inhibition of serotonin release in the mouse brain via presynaptic cannabinoid CB1 receptors. Naunyn-Schmiedebergs Arch. Pharmacol. 361, 19-24. doi: 10.1007/s002109900147

Navarro, M., Hernández, E., Muñoz, R. M., Del Arco, I., Villanua, M. A., Carrera, M. R., et al. (1997). Acute administration of the CB1 cannabinoid receptor antagonist SR 141716A induces anxiety-like responses in the rat. NeuroReport 8, 491-496. doi: 10.1097/00001756-199701200-00023

Nestler, E. J., and Carlezon, W. A. Jr. (2006). The mesolimbic dopamine reward circuit in depression. Biol. Psychiatry 59, 1151-1159. doi: 10.1016/j.biopsych.2005.09.018

Neumeister, A., Normandin, M. D., Pietrzak, R. H., Piomelli, D., Zheng, M. Q., et al. (2013). Elevated brain cannabinoid CB1 receptor availability in post-traumatic stress disorder: a positron emission tomography study. Mol. Psychiatry 18, 1034-1040. doi: 10.1038/mp.2013.61

Norman, G. J., Karelina, K., Zhang, N., Walton, J. C., Morris, J. S., and Devries, A. C. (2010). Stress and IL-1beta contribute to the development of depressivelike behavior following peripheral nerve injury. Mol. Psychiatry 15, 404-414. doi: $10.1038 / \mathrm{mp} .2009 .91$

Onaivi, E. S., Ishiguro, H., Gong, J. P., Patel, S., Meozzi, P. A., Myers, L., et al. (2008). Brain neuronal CB2 cannabinoid receptors in drug abuse and depression: from mice to human subjects. PLoS ONE 3:e1640. doi: 10.1371/journal.pone. 0001640

Pacher, P., and Kunos, G. (2013). Modulating the endocannabinoid system in human health and disease-successes and failures. FEBS J. 280, 1918-1943. doi: $10.1111 /$ febs. 12260

Padwal, R. S., and Majumdar, S. R. (2007). Drug treatments for obesity: orlistat, sibutramine, and rimonabant. Lancet 369, 71-77. doi: 10.1016/s0140-6736(07)60033-6

Panagis, G., Mackey, B., and Vlachou, S. (2014). Cannabinoid regulation of brain reward processing with an emphasis on the role of CB1 receptors: a step back into the future. Front. Psychiatry 5:92. doi: 10.3389/fpsyt.2014.00092

Pandey, R., Mousawy, K., Nagarkatti, M., and Nagarkatti, P. (2009). Endocannabinoids and immune regulation. Pharmacol. Res. 60, 85-92. doi: 10.1016/j.phrs.2009.03.019

Parsons, L. H., and Hurd, Y. L. (2015). Endocannabinoid signalling in reward and addiction. Nat. Rev. Neurosci. 16, 579-594. doi: 10.1038/nrn4004

Patel, S., and Hillard, C. J. (2006). Pharmacological evaluation of cannabinoid receptor ligands in a mouse model of anxiety: further evidence for an anxiolytic role for endogenous cannabinoid signaling. J. Pharmacol. Exp. Ther. 318, 304-311. doi: 10.1124/jpet.106.101287

Patel, S., Roelke, C. T., Rademacher, D. J., and Hillard, C. J. (2005). Inhibition of restraint stress-induced neural and behavioural activation by endogenous cannabinoid signalling. Eur. J. Neurosci. 21, 1057-1069. doi: 10.1111/j.1460-9568.2005.03916.x

Patten, S. B., Beck, C. A., Williams, J. V., Barbui, C., and Metz, L. M. (2003). Major depression in multiple sclerosis: a population-based perspective. Neurology 61, 1524-1527. doi: 10.1212/01.wnl.0000095964.34294.b4

Pietrzak, R. H., Huang, Y., Corsi-Travali, S., Zheng, M.-Q., Lin, S.-F., Henry, S.-N., et al. (2014). Cannabinoid type I receptor availability in the amygdala mediates threat processing in trauma survivors. Neuropsychopharmacology 39, 2519-2528. doi: 10.1038/npp.2014.110

Pollak, Y., Ovadia, H., Goshen, I., Gurevich, R., Monsa, K., Avitsur, R., et al. (2000). Behavioral aspects of experimental autoimmune encephalomyelitis. $J$. Neuroimmunol. 104, 31-36. doi: 10.1016/s0165-5728(99)00257-x

Pollak, Y., Ovadia, H., Orion, E., Weidenfeld, J., and Yirmiya, R. (2003). The EAEassociated behavioral syndrome: I. Temporal correlation with inflammatory mediators. J. Neuroimmunol. 137, 94-99. doi: 10.1016/s0165-5728(03)00075-4

Rademacher, D. J., and Hillard, C. J. (2007). Interactions between endocannabinoids and stress-induced decreased sensitivity to natural reward. Prog. Neuropsychopharmacol. Biol. Psychiatry 31, 633-641. doi: 10.1016/j.pnpbp.2006.12.013

Rademacher, D. J., Meier, S. E., Shi, L., Ho, W. S., Jarrahian, A., and Hillard, C. J. (2008). Effects of acute and repeated restraint stress on endocannabinoid content in the amygdala, ventral striatum, and medial prefrontal cortex in mice. Neuropharmacology 54, 108-116. doi: 10.1016/j.neuropharm.2007.06.012

Raison, C. L., Capuron, L., and Miller, A. H. (2006). Cytokines sing the blues: inflammation and the pathogenesis of depression. Trends Immunol. 27, 24-31. doi: 10.1016/j.it.2005.11.006

Reichenberg, A., Yirmiya, R., Schuld, A., Kraus, T., Haack, M., Morag, A., et al. (2001). Cytokine-associated emotional and cognitive disturbances in humans. Arch. Gen. Psychiatry 58, 445-452. doi: 10.1001/archpsyc.58.5.445

Riazi, K., Galic, M. A., Kuzmiski, J. B., Ho, W., Sharkey, K. A., and Pittman, Q. J. (2008). Microglial activation and TNFalpha production mediate altered CNS excitability following peripheral inflammation. Proc. Natl. Acad. Sci. U.S.A. 105, 17151-17156. doi: 10.1073/pnas.0806682105

Rigotti, N. A., Gonzales, D., Dale, L. C., Lawrence, D., and Chang, Y., for the, C. I. R. R. U. S., Study Group (2009). A randomized controlled trial of adding the nicotine patch to rimonabant for smoking cessation: efficacy, safety and weight gain. Addiction 104, 266-276. doi: 10.1111/j.1360-0443.2008.02454.x 
Rossi, S., De Chiara, V., Musella, A., Kusayanagi, H., Mataluni, G., Bernardi, G., et al. (2008). Chronic psychoemotional stress impairs cannabinoid-receptormediated control of GABA transmission in the striatum. J. Neurosci. 28, 7284-7292. doi: 10.1523/JNEUROSCI.5346-07.2008

Rossi, S., Furlan, R., De Chiara, V., Muzio, L., Musella, A., Motta, C., et al. (2011). Cannabinoid CB1 receptors regulate neuronal TNF- $\alpha$ effects in experimental autoimmune encephalomyelitis. Brain Behav. Immun. 25, 1242-1248. doi: 10.1016/j.bbi.2011.03.017

Rossi, S., Sacchetti, L., Napolitano, F., De Chiara, V., Motta, C., Studer, V., et al. (2012). Interleukin-1 $\beta$ causes anxiety by interacting with the endocannabinoid system. J. Neurosci. 32, 13896-13905. doi: 10.1523/JNEUROSCI.1515-12.2012

Schiffer, R. B., and Babigian, H. M. (1984). Behavioral disorders in multiple sclerosis, temporal lobe epilepsy and amyotrophic lateral sclerosis. An epidemiologic study. Arch. Neurol. 41, 1067-1069. doi: 10.1001/archneur.1984.04050210065016

Schubert, D. S., and Foliart, R. H. (1993). Increased depression in multiple sclerosis: a meta-analysis. Psychosomatics 34, 124-130. doi: 10.1016/s0033-3182(93)71902-7

Sidhpura, N., and Parsons, L. H. (2011). Endocannabinoid-mediated synaptic plasticity and addiction-related behavior. Neuropharmacology 61, 1070-1087. doi: 10.1016/j.neuropharm.2011.05.034

Silvestri, C., and Di Marzo, V. (2013). The endocannabinoid system in energy homeostasis and the etiopathology of metabolic disorders. Cell Metab. 17, 475-490. doi: 10.1016/j.cmet.2013.03.001

Simiand, J., Keane, M., Keane, P. E., and Soubrié, P. (1998). SR 141716, a CB1 cannabinoid receptor antagonist, selectively reduces sweet food intake in marmoset. Behav. Pharmacol. 9, 179-181.

Stella, N. (2009). Endocannabinoid signaling in microglial cells. Neuropharmacology 56, 244-253. doi: 10.1016/j.neuropharm.2008. 07.037

Strawbridge, R., Arnone, D., Danese, A., Papadopoulos, A., Herane Vives, A., and Cleare, A. J. (2015). Inflammation and clinical response to treatment in depression: a meta-analysis. Eur. Neuropsychopharmacol. 25, 1532-1543. doi: 10.1016/j.euroneuro.2015.06.007

Su, F., Yi, H., Xu, L., and Zhang, Z. (2015). Fluoxetine and S-citalopram inhibit M1 activation and promote M2 activation of microglia in vitro. Neuroscience 294, 60-68. doi: 10.1016/j.neuroscience.2015.02.028

Suh, Y., Motl, R. W., and Mohr, D. C. (2010). Physical activity, disability, and mood in the early stage of multiple sclerosis. Disabil. Health J. 3, 93-98. doi: 10.1016/j.dhjo.2009.09.002

Thielscher, C., Thielscher, S., and Kostev, K. (2013). The risk of developing depression when suffering from neurological diseases. Ger. Med. Sci. 11, 1-7. doi: 10.3205/000170

Tóth, A., Blumberg, P. M., and Boczán, J. (2009). Anandamide and the vanilloid receptor (TRPV1). Vitam Horm. 81, 389-419. doi: 10.1016/S0083-6729(09)81015-7

Traynor, K. (2007). Panel advises against rimonabant approval. Am. J. Health Syst. Pharm. 64, 1460-1461. doi: 10.2146/news070065

Trezza, V., Baarendse, P. J. J., and Vanderschuren, L. J. M. J. (2010). The pleasures of play: pharmacological insights into social reward mechanisms. Trends Pharmacol. Sci. 31, 463-469. doi: 10.1016/j.tips.2010.06.008

Turna, J., Patterson, B., and Van Ameringen, M. (2017). Is cannabis treatment for anxiety, mood, and related disorders ready for prime time? Depress. Anxiety 34, 1006-1017. doi: 10.1002/da.22664

Tyndale, R. F., Payne, J. I., Gerber, A. L., and Sipe, J. C. (2007). The fatty acid amide hydrolase C385A (P129T) missense variant in cannabis users: studies of drug use and dependence in Caucasians. Am. J. Med. Genet. B Neuropsychiatr. Genet. 144B, 660-666. doi: 10.1002/ajmg.b.30491

Tyring, S., Gottlieb, A., Papp, K., Gordon, K., Leonardi, C., Wang, A., et al. (2006). Etanercept and clinical outcomes, fatigue, and depression in psoriasis: double-blind placebo-controlled randomized phase III trial. Lancet 367, 29-35. doi: 10.1016/S0140-6736(05)67763-X

Urigüen, L., Pérez-Rial, S., Ledent, C., Palomo, T., and Manzanares, J. (2004). Impaired action of anxiolytic drugs in mice deficient in cannabinoid CB1 receptors. Neuropharmacology 46, 966-973. doi: 10.1016/j.neuropharm.2004.01.003

Uriguen, L., Perez-Rial, S., Ortiz, S., Oliva, J. M., Palomo, T., and Manzanares, J. (2003). Altered emotional states and impaired anxiolytic action of benzodiacepines in mice lacking cannabinoid CB1 receptors. Eur. Neuropsychopharm. 13, S373. doi: 10.1016/S0924-977X(03)92166-3

van Dam, A. M., Brouns, M., Louisse, S., and Berkenbosch, F. (1992). Appearance of interleukin-1 in macrophages and in ramified microglia in the brain of endotoxin-treated rats: a pathway for the induction of nonspecific symptoms of sickness? Brain Res. 588, 291-296. doi: 10.1016/0006-8993(92) 91588-6

Van Gaal, L. F., Rissanen, A. M., Scheen, A. J., Ziegler, O., Rössner, S., for the RIO-Europe Study Group. (2005). Effects of the cannabinoid-1 receptor blocker rimonabant on weight reduction and cardiovascular risk factors in overweight patients: 1-year experience from the RIO-Europe study. Lancet 365, 1389-1397. doi: 10.1016/S0140-6736(05)66374-X

Volkow, N. D., Baler, R. D., Compton, W. M., and Weiss, S. R. B. (2014). Adverse health effects of marijuana use. N. Engl. J. Med. 370, 2219-2227. doi: 10.1056/NEJMra1402309

Wager, T. D., Scott, D. J., and Zubieta, J. K. (2007). Placebo effects on human mu-opioid activity during pain. Proc. Natl. Acad. Sci. U.S.A. 104, 11056-11061. doi: 10.1073/pnas.0702413104

Walsh, Z., Gonzalez, R., Crosby, K., Thiessen, M. S., Carroll, C., and BonnMiller, M. O. (2017). Medical cannabis and mental health: a guided systematic review. Clin. Psychol. Rev. 51, 15-29. doi: 10.1016/j.cpr.2016. 10.002

Wang, X., Dow-Edwards, D., Keller, E., and Hurd, Y. L. (2003). Preferential limbic expression of the cannabinoid receptor mRNA in the human fetal brain. Neuroscience 118, 681-694. doi: 10.1016/S0306-4522(03)0 0020-4

Ward, S. J., and Dykstra, L. A. (2005). The role of CB1 receptors in sweet versus fat reinforcement: effect of $\mathrm{CB} 1$ receptor deletion, $\mathrm{CB} 1$ receptor antagonism (SR141716A) and CB1 receptor agonism (CP-55940). Behav. Pharmacol. 16, 381-388. doi: 10.1097/00008877-200509000-00010

Whiting, P. F., Wolff, R. F., Deshpande, S., Di Nisio, M., Duffy, S., Hernandez, A. V., et al. (2015). Cannabinoids for medical use: a systematic review and meta-analysis. JAMA 313, 2456-2473. doi: 10.1001/jama.2015.6358

Wilson, R. I., and Nicoll, R. A. (2002). Endocannabinoid signaling in the brain. Science 296, 678-682. doi: 10.1126/science.1063545

Zeher, H., Amin, M. E., and Rakhawy, M. Y. (2010). Coping with depression and anxiety in patients with psoriasis. Egypt. J. Psychiatry 31, 57-63.

Zhang, H. T., Huang, Y., Masood, A., Stolinski, L. R., Li, Y., Zhang, L., et al. (2008). Anxiogenic-like behavioral phenotype of mice deficient in phosphodiesterase 4B PDE4B. Neuropsychopharmacology 33, 1611-1623. doi: $10.1038 /$ sj.npp. 1301537

Zhang, L., and Xiong, W. (2009). Modulation of the Cys-loop ligand-gated ion channels by fatty acid and cannabinoids. Vitam. Horm. 81, 315-335. doi: 10.1016/S0083-6729(09)81012-1

Zhang, P. W., Ishiguro, H., Ohtsuki, T., Hess, J., Carillo, F., Walther, D., et al. (2004). Human cannabinoid receptor 1: 5 ' exons, candidate regulatory regions, polymorphisms, haplotypes and association with polysubstance abuse. Mol. Psychiatry 9, 916-931. doi: 10.1038/sj.mp.4001560

Zorrilla, E. P., Luborsky, L., McKay, J. R., Rosenthal, R., Houldin, A., Tax, A., et al. (2001). The relationship of depression and stressors to immunological assays: a meta-analytic review. Brain Behav. Immun. 15, 199-226. doi: 10.1006/brbi.2000.0597

Zuo, L., Kranzler, H. R., Luo, X., Covault, J., and Gelernter, J. (2007). CNR1 variation modulates risk for drug and alcohol dependence. Biol. Psychiatry 62 , 616-626. doi: 10.1016/j.biopsych.2006.12.004

Conflict of Interest Statement: The authors declare that the research was conducted in the absence of any commercial or financial relationships that could be construed as a potential conflict of interest.

Copyright (C) 2018 Stampanoni Bassi, Gilio, Maffei, Dolcetti, Bruno, Buttari, Centonze and Iezzi. This is an open-access article distributed under the terms of the Creative Commons Attribution License (CC BY). The use, distribution or reproduction in other forums is permitted, provided the original author(s) and the copyright owner(s) are credited and that the original publication in this journal is cited, in accordance with accepted academic practice. No use, distribution or reproduction is permitted which does not comply with these terms. 